\title{
Transformation of Terpenoids in Grape Must by Botrytis cinerea
}

\author{
Jun-ichi Shimizu, Mikio Uehara and Masazumi Watanabe \\ Central Research Laboratories of Kikkoman Corporation, \\ 399-Noda, Noda, Chiba 278, Japan
}

Received November 25, 1981

\begin{abstract}
Experiments were done to investigate the volatile components in botrytized grape must and transformation of terpenoids in terpene-supplemented grape must by Botrytis cinerea. Twenty-eight compounds were identified in the volatile concentrate of botrytized must with a combined gas chromatograph-mass spectrometer. No terpenoids were detected in the concentrate. Linalool or terpinen-4-ol decreased a lot when Botrytis cinerea was cultured in the must with these terpenes for 15 days. In linalool-supplemented botrytized must 9 identified and 3 unidentified terpenes were found, while only geranial was detected in terpinen-4-ol-supplemented botrytized must. Botrytis cinerea did not produce terpenoid in grape must without terpenes, but transformed linalool added to grape must into some other monoterpenes.
\end{abstract}

Mono and sesquiterpenoids are primarily plant products and are well known as characteristic components of a variety of essential oils. The presence of these compounds in grapes and wines was reported by many investigators $^{1 \sim 6)}$ and about 20 monoterpenoids have hitherto been found in Muscat and wine grapes. $^{7 \sim 10)}$

Biosynthetic pathways of terpenoids in plants have already been proposed by Croteau $^{11)}$ and the formation of these compounds by fungi has been elucidated by Collins et al. ${ }^{12,13)}$ Furthermore, Tressl et al. ${ }^{14)}$ have reviewed in detail the isomerization and stereospecific reaction of terpenoids by fungi. Recently, advanced studies were performed on the formation of terpenoids by yeast ${ }^{15)}$ and bacteria. ${ }^{16)}$

Noble wine is made from botrytized grapes. Involvement of the fungus, Botrytis cinerea, and wine yeasts is responsible for noble wine making ${ }^{17,18)}$ and especially for characteristic fragrant flavor development. ${ }^{19,20)}$ One step of this flavor formation seemed to be that terpenoids in grapes are changed into more fragrant flavors by the action of Botrytis cinerea attacking the grape skin. However, only a few studies have been reported on the flavor com- ponents formed by this fungus. ${ }^{21)}$

This paper deals with the identification of volatile components produced by Botrytis cinerea using combined gas chromatographymass spectrometry and with the transformation of terpenes added to artificially botrytized grape must into other terpenic compounds by this fungus.

\section{MATERIALS AND METHODS}

Microorganism. Botrytis cinerea BIG (IFO 5964) was obtained from the culture collection of microorganisms of the Institute of Microbiology and Biochemistry, Geisenheim, Federal Republic of Germany.

Grape must. The must used in this experiment was supplemented with sucrose to $25 \%$ sugar content. The prepared must contained $3.18 \mathrm{~g}$ total acids per liter ( $\mathrm{pH}$ $3.70)$ and was free of terpenic compounds.

Cultivation. To $300 \mathrm{ml}$ prepared must $120 \mathrm{mg}$ sodium salt of adenosine- $3^{\prime}, 5^{\prime}$-cyclic monophosphate (c-AMP) was added as a growth stimulator of Botrytis cinerea ${ }^{22)}$ and in some cases $6 \mathrm{mg}$ each of linalool, linalool oxide (mixture of cis and trans forms), terpinen-4-ol or $\alpha$-terpineol was further added. After inoculation of a loopful of Botrytis cinerea spores, the must in $500 \mathrm{ml}$ Sakaguchi flasks was incubated on a reciprocal shaker with $70-\mathrm{mm}$ amplitude at 130 strokes per minute at $15^{\circ} \mathrm{C}$ for 15 days. 
Chemicals. Sodium salt of c-AMP was donated by Seishin Pharmaceutical Co. Ltd., Tokyo. Linalool from Tokyo Kasei Kogyo Co. Ltd., Tokyo, and linalool oxide, $\alpha$-terpineol and terpinen-4-ol from Merck, München, were of analytical grade for gas chromatography, respectively.

Preparation of volatile concentrate. Volatile components from $200 \mathrm{ml}$ out of $300 \mathrm{ml}$ of botrytized musts were directly extracted twice with $100 \mathrm{ml}$ of purified dichloromethane by shaking for 30 minutes at room temperature. The separated dichloromethane layer was washed 3 times with distilled water and dried over anhydrous $\mathrm{Na}_{2} \mathrm{SO}_{4}$. The solvent layer was concentrated to about $0.2 \mathrm{ml}$ at room temperature in vacuo.

Calibration curves and determination of terpenes. Calibration curves to determine terpenes were obtained as follows. Standard reagents of linalool, linalool oxide, terpinen-4-ol and $\alpha$-terpineol were diluted to $5,10,20,30$ and $40 \mu \mathrm{g}$ per liter each with $20 \mathrm{ml}$ of the must not containing detectable amounts of these compounds. To the above must $20 \mu \mathrm{g}$ of diethyl succinate (DES) as the internal standard and $20 \mathrm{ml}$ of purified dichloromethane were added. After the mixture was mechanically stirred for 15 minutes, the solvent layer was separated and concentrated at room temperature in vacuo. A portion of the concentrate was injected on a glass column $(2 \mathrm{~mm}$ i.d. $\times 3 \mathrm{~m})$ packed with 60 to 80 mesh chromosorb W (AWDMCS) coated with $10 \%$ PEG $20 \mathrm{M}$ TPA. The oven temperature was programmed from $70^{\circ} \mathrm{C}$ to $250^{\circ} \mathrm{C}$ at a rate of $5^{\circ} \mathrm{C} / \mathrm{min}$. Both injection and detection temperatures were set at $300^{\circ} \mathrm{C}$ and the flow rate of carrier gas $\left(\mathrm{N}_{2}\right)$ was $30 \mathrm{ml} / \mathrm{min}$. Then, the standard curves were got by plotting the ratio of peak height on the gas chromatogram of terpenes to that of the internal standard (DES) versus concentration. In the determination of terpenic compounds in botrytized musts, terpenes were extracted with purified dichloromethane after mixing a $2 \mathrm{ml}$ sample, $18 \mathrm{ml}$ deionized water and $20 \mu \mathrm{g}$ DES.
Capillary column gas chromatographic-mass spectrometric analysis (Capillary GC-MS). Volatile components in the concentrates from botrytized musts were identified with a combined gas chromatograph-mass spectrometer using a capillary column. The all-glass jet separator used at the GC-MS interface was heated at $250^{\circ} \mathrm{C}$. The conditions for gas chromatography were as follows: a $0.28 \mathrm{~mm}$ (i.d.) $\times 30 \mathrm{~m}$ glass capillary column coated with FFAP (G-SCOT), helium pressure of $0.2 \mathrm{~kg} / \mathrm{cm}^{2}$ (flow rate: $0.7 \mathrm{ml} / \mathrm{min}$ ), split ratio of $100: 1$ and injection temperature of $230^{\circ} \mathrm{C}$. The oven temperature was programmed from $50^{\circ} \mathrm{C}$ to $170^{\circ} \mathrm{C}$ at a rate of $3^{\circ} \mathrm{C} / \mathrm{min}$. The mass spectrometer was operated under the conditions of ionization electron energy of $70 \mathrm{eV}$ and an ion source temperature of $240^{\circ} \mathrm{C}$.

\section{RESULTS AND DISCUSSION}

The calibration curves of 4 terpenes were linear up to $40 \mu \mathrm{g}$ of each terpene under the assay conditions mentioned above and were not influenced by sucrose up to $25 \%$ or by ethanol up to $20 \%$.

Table I shows the changes of the 4 terpenes artificially added to botrytized must. Although linalool oxide was unchanged, the amounts of the other 3 terpenes decreased, more or less, during incubation with Botrytis cinerea. However, no relation was seen between the decrease of terpenes and the fungal growth. It was assumed, therefore, that the 3 terpenes might be converted by the fungus to other compounds. To confirm this presumption, volatile concentrates prepared from the botrytized musts with or without terpene were subjected to GC-MS.

Table I. Changes of the Terpenic Compounds in

TERPENE-SUPPLEMENTED BOTRYTIZED MUST

\begin{tabular}{|c|c|c|c|}
\hline \multirow{2}{*}{ Terpenes added } & \multicolumn{2}{|c|}{ Amounts (mg/liter) } & \multirow{2}{*}{$\begin{array}{c}\text { Growth of Botrytis } \\
\text { cinerea }^{b}\end{array}$} \\
\hline & Added & Residual & \\
\hline None (control) & 0 & & 100 \\
\hline Linalool & 20 & 7.14 & 40 \\
\hline Furan-linalool oxide ${ }^{a}$ & 20 & $\begin{array}{l}9.11 \text { (trans-form) } \\
11.20 \text { (cis-form) }\end{array}$ & 90 \\
\hline Terpinen-4-ol & 20 & 5.12 & 80 \\
\hline$\alpha$-Terpineol & 20 & 15.74 & 50 \\
\hline
\end{tabular}

a Mixture of trans- and cis-forms.

b Percentage of mycelial weight of the fungus to that of control. 

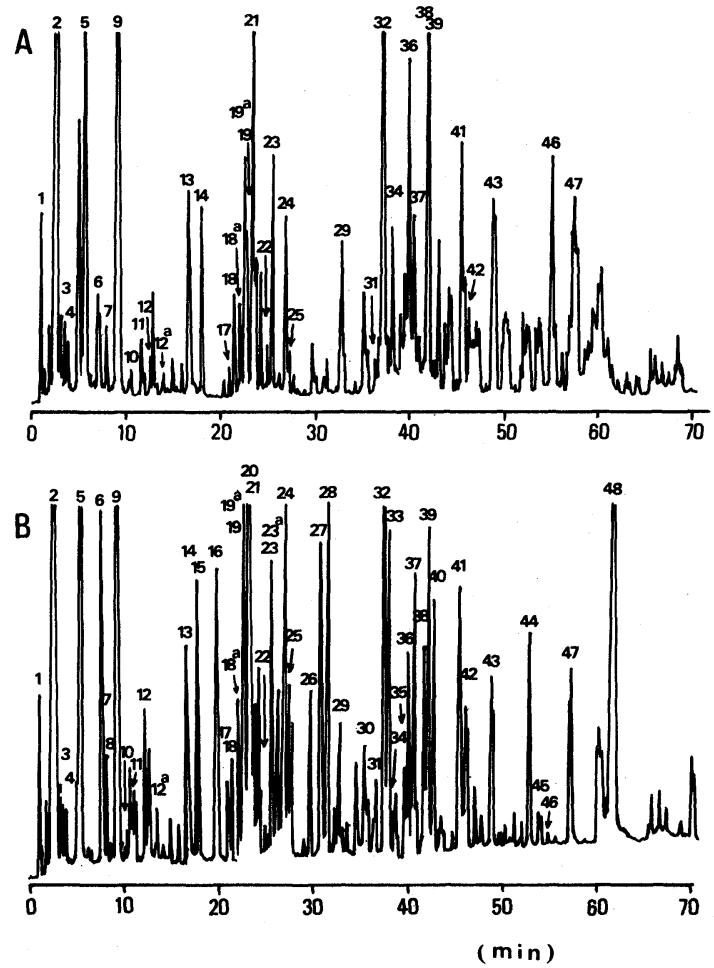

FIG. 1. Gas Chromatograms of Volatile Concentrates from Botrytized Grape Musts.

A: In the absence of terpene. B: In the presence of linalool. Peak numbers correspond to those in Table II.

Table II. IDEnTIFIEd Volatile Components IN NON-SUPPLEMENTED AND LINALOOLSUPPLEMENTED BOTRYTIZED MUSTS

\begin{tabular}{rll}
$\begin{array}{c}\text { Peak } \\
\text { Nos. }\end{array}$ & \multicolumn{1}{c}{ Compounds* } & $\begin{array}{c}\text { Methods of } \\
\text { identification** }\end{array}$ \\
\hline 1 & Carbon dioxide & MS \\
2 & Dichloromethane (Solvent) & MS \\
3 & 1-Propanol & MS, GC \\
4 & 2-Butanol & MS, GC \\
5 & 2-Methyl-1-propanol & MS, GC \\
6 & 1-Butanol & MS, GC \\
7 & 3-Pentene-2-ol & MS \\
8 & $\beta$-Pinene & MS \\
9 & 3-Methyl-1-butanol & MS, GC \\
10 & 1-Pentanol & MS, GC \\
11 & 2-Methylpyrazine & MS \\
12 & 1-Hydroxy-2-propanone & MS \\
$12^{\text {a }}$ & Ethylpyrazine & MS \\
13 & Acetic acid & MS, GC \\
14 & 2-Furaldehyde & MS, GC \\
15 & trans-Furan-linalool oxide & MS, GC \\
16 & cis-Furan-linalool oxide & MS, GC
\end{tabular}

17 Benzaldehyde MS, GC

18 Propionic acid MS, GC

$18^{\mathrm{a}}$ 2,3-Butandiol (levo) MS, GC

19 2-Methylpropionic acid MS, GC

$19^{\text {a }}$ Pyrazine MS

20 Linalool (Added) MS, GC

21 5-Methyl-2-furaldehyde MS

22 Butanoic acid MS, GC

$23 \gamma$-Butyrolactone MS, GC

$23^{a} p$-Menthane-1-ene-3-one MS

$24 \alpha$-Furfuryl alcohol MS, GC

25 3-Methylpentanoic acid MS, GC

$26 \alpha$-Terpineol MS, GC

27 trans-Pyran-linalool oxide MS

28 cis-Pyran-linalool oxide MS

29 5-Hydroxypentanoic acid lactone MS

30 Geraniol MS, GC

31 Benzyl alcohól MS, GC

32. 2-Phenylethanol MS, GC

33 Unidentified terpene MS

34 2,6-di-tert-Butyl-4-

35 2-Acetopyrrole MS

36 2-Methoxy-6-methylpyrazine MS

37 Methyl furoate MS

38 N. I.

39 N. I.

40 p-Menthane-1,8-diene-9-ol MS

41 2,5-Hexadione MS

42 tert-Butyl-2-methoxyphenol MS

43 N. I.

44 Unidentified terpene MS

45 2-Methyl-2-tert-butylphenol MS

46 N. I.

47 N. I.

48 Unidentified terpene MS

* N. I., not identified.

** MS, mass spectrometry; GC, retention time on gas chromatography with authentic samples.

Peak numbers correspond to those in Figs. 1-A and $1-B$.

Figures 1-A and 1-B respectively show the gas chromatograms of volatile concentrates from the botrytized musts in the absence and presence of linalool. Table II lists the identified compounds in both musts. Most of the 28 compounds detected in ordinary botrytized must were further confirmed by gas chromatography with authentic samples. They were flavor components of the grape must and the products of Botrytis cinerea. Various furan and nitrogenous compounds were discovered in the flavor components. However, no ter- 
Table III. Mass Spectral Data and Amounts of Terpenic Compounds Found in TERPENE-SUPPLEMENTED BOTRYTIZED MUSTS

\begin{tabular}{|c|c|c|c|c|c|}
\hline \multirow{2}{*}{ Added } & \multicolumn{2}{|r|}{ Found } & \multirow{2}{*}{$\mathbf{M}^{+}$or $\mathbf{M W}^{*}$} & \multirow{2}{*}{$m / z$ (Relative intensity, $\%)$} & \multirow{2}{*}{$\begin{array}{c}\text { Amounts** } \\
(\mathrm{mg} / \mathrm{ltter})\end{array}$} \\
\hline & Peak Nos. & Compounds & & & \\
\hline \multirow{12}{*}{ Linalool } & 8 & $\beta$-Pinene & 136 & 93 (100), 41 (75), 69 (49), 39 (35), 27 (32), 79 (20) & 0.05 \\
\hline & 15 & trans-Furan-linalool oxide & $170^{*}$ & $59(100), 43(43), 94(42), 111(34), 55(30), 68(30)$ & 0.65 \\
\hline & 16 & cis-Furan-linalool oxide & $170^{*}$ & $59(100), 94(42), 43(41), 111(33), 55(31), 68(30)$ & 0.69 \\
\hline & $23^{\mathrm{a}}$ & $p$-Menthane-1-ene-3-one & 152 & $82(100), 110(56), 95(23), 41(23), 137(17), 109(17)$ & - \\
\hline & 26 & $\alpha$-Terpineol & 154 & $59(100), 93(75), 136(72), 121(72), 43(42), 81(35)$ & 0.39 \\
\hline & 27 & trans-Pyran-linalool oxide & $170^{*}$ & $68(100), 59(86), 94(75), 67(47), 43(39), 55(21)$ & 0.75 \\
\hline & 28 & $c l s$-Pyran-linalool oxide & $170^{*}$ & $68(100), 59(85), 94$ (75), 67 (47), 43 (38), $55(23)$ & 1.01 \\
\hline & 30 & Geraniol & 154 & 69 (100), 93 (35), 41 (28), 68 (24), 84 (15), $123(15)$ & 0.15 \\
\hline & 33 & Unidentified terpene & 134 & 43 (100), 93 (98), 79 (43), 41 (43), 91 (36), 119 (23) & 0.81 \\
\hline & 40 & $p$-Menthane-1,8-diene-9-ol & 152 & $79(100), 93(93), 92(75), 91(74), 41(69), 119(63)$ & 0.53 \\
\hline & 44 & Unidentified terpene & 154 & $71(100), 43(63), 55(43), 69(29), 41(29), 56(21)$ & 0.39 \\
\hline & 48 & Unidentified terpene & 152 & 43 (100), 71 (97), 67 (94), 55 (58), 68 (47), $82(41)$ & 7.47 \\
\hline Terpinen-4-ol & & Geranial & 152 & $69(100), 41(65), 84(30), 39(22), 94(16), 27$ (11) & 0.24 \\
\hline
\end{tabular}

* Molecular weight.

** Determined by gas chromatography. - , not determined. 


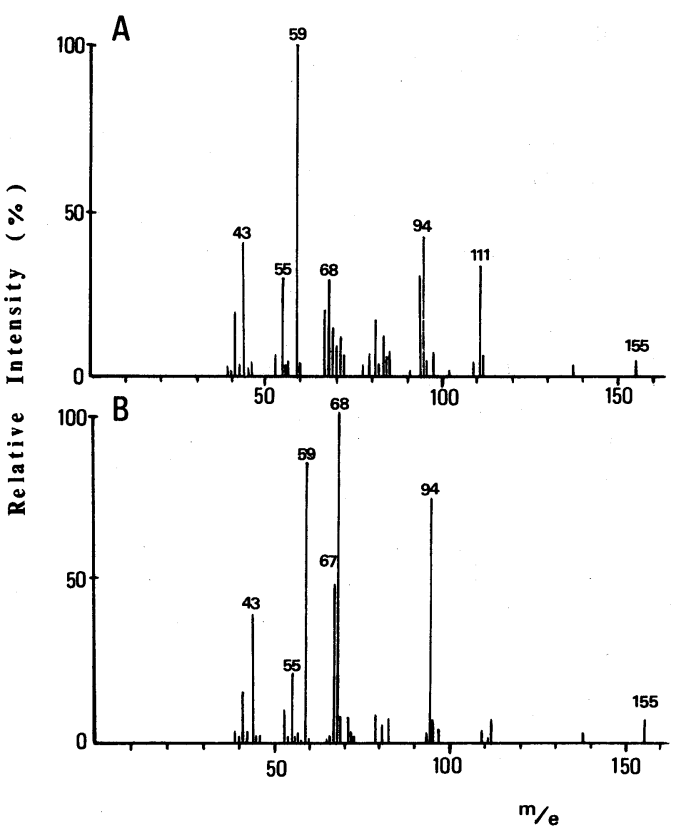

FIG. 2. Mass Spectra of trans-Furan- and trans-Pyranlinalool Oxides Isolated from Botrytized Must and Their Suggested Fragmentations.

A: trans-Furan-linalool oxide. B: trans-Pyran-linalool oxide.

penoids were found in the must although many unknown non-terpenic peaks appeared on the gas chromatogram. From the above results, it was clarified that Botrytis cinerea did not produce terpenoid in the must under the culture conditions previously described. On the other hand, in the presence of linalool 12 more terpenoids in addition to the above compounds were detected in the volatile concentrate of the botrytized must. They were $\beta$ pinene (peak No. 8), trans-furan-linalool oxide (peak No. 15), cis-furan-linalool oxide (peak No. 16), $p$-menthane-1-ene-3-one (peak No. $23^{\mathrm{a}}$ ), $\alpha$-terpineol (peak No. 26), trans-pyranlinalool oxide (peak No. 27), cis-pyran-linalool oxide (peak No. 28), geraniol (peak No. 30), $p$ menthane-1,8-diene-9-ol (peak No. 40) and 3 unidentified monoterpenes (peak Nos. 33, 44 and 48). Some of them were further confirmed by gas chromatography with authentic samples. Table III displays the mass spectral data and amounts of these terpenes. Williams et $a l .{ }^{10)}$ have already reported the presence of 7 of the above monoterpenes except $p$ menthane-1-ene-3-one and $p$-menthane-1,8diene-9-ol in the must of Muscat of Alexandria grapes without description of their amounts. It is noteworthy that the decreased amount of linalool is very close to the total amounts of the 12 terpenes produced (see Tables I and III). Figure 2 illustrates the mass spectra of furan and pyran types of trans-linalool oxide isolated from the must and their suggested fragmentations. The spectra of stereoisomers (cis and trans forms) of furan-linalool oxide or pyranlinalool oxide were respectively very similar to each other. The above results suggested that Botrytis cinerea transformed linalool to some other monoterpenes.

In the presence of terpinen-4-ol only geranial was found as a terpenic compound and no other terpene was detected in the botrytized must (Table III). Most of the terpinen-4-ol is considered to be transformed to other nonterpenic compounds by Botrytis cinerea based on the amounts of terpinen-4-ol and geranial in the must (Tables I and III).

In view of the above results it is presumed that acyclic monoterpenoids such as linalool in grapes are easily converted to other terpenic compounds by Botrytis cinerea in the process of noble wine making from botrytized grapes and this transformation is one of the factors in the development of the characteristic flavor of noble wine.

Acknowledgments. The authors wish to express their gratitude to Dr. S. Nasuno for his help in preparing this manuscript and to Dr. N. Iguchi and Dr. F. Yoshida for their encouragement.

\section{REFERENCES}

1) A. Terrier et J. N. Boidron, Connaissance de la Vigne et $d u$ Vin, No. 2, 147 (1972)

2) P. Ribéreau-Gayon, J. N. Boidron and A. Terrier, $J$. Agric. Food Chem., 23, 1042 (1975).

3) P. Schreier, F. Drawert und A. Junker, Z. Lebensm. Unters.-Forsch., 160, 271 (1976).

4) A. Rapp, $X \mathrm{XI}^{\mathrm{e}}$ Congrès International de la Vigne et du Vin, Stuttgart, $21 \sim 27$ Mai, 1979, p. 3.

5) P. Schreier, F. Drawert and A. Junker, J. Agric. Food Chem., 24, 331 (1976).

6) P. Schreier, F. Drawert, A. Junker and L. Reiner, 
Mitt. Klosterneuburg, 26, 225 (1976).

7) A. Rapp, W. Knipser und L. Engel, Vitis, 19, 226 (1980).

8) P. J. Williams, C. R. Strauss and B. Wilson, Phytochemistry, 19, 1137 (1980).

9) P. J. Williams, C. R. Strauss and B. Wilson, Aust. Grapegrower and Winemaker, 17, 10 (1980).

10) P. J. Williams, C. R. Strauss and B. Wilson, J. Agric. Food Chem., 28, 766 (1980).

11) R. Croteau, "Geruh- und Geschmackstoffe," ed. by F. Drawert, Verlag Hans Carl, Nürnberg, 1975, p. 153.

12) R. P. Collins and A. F. Halim, Lloydia, 33, 481 (1970).

13) A. F. Halim and R. P. Collins, Lloydia, 34, 451 (1971).

14) R. Tressl, M. Apetz, R. Arrieta and K. G. Grünewald, "Flavor of Foods and Beverages, Chemistry and Technology," Academic Press Inc.,
New York, 1978, p. 145.

15) G. L. Fagan, R. E. Kepner and A. D. Webb, Vitis, 20, 36 (1981).

16) T. Oritani and K. Yamashita, Agric. Biol. Chem., 44, 2637 (1980).

17) M. Watanabe and Y. Shimazu, J. Ferment. Technol., 54, 491 (1976).

18) H. Schanderl, "Microbiologie des Mostes und Weines," E. Ulmer, 1959, p. 202.

19) P. Schreier, F. Drawert, Z. Kerenyi und A. Junker, Z. Lebensm. Unters.-Forsch., 161, 249 (1976).

20) H. Yunome, K. Nishimura, M. Masuda, Y. Zenibayashi and E. Ohkawa, Hakko Kogaku, 59, 177 (1981).

21) J. N. Boidron et F. Leveque, Rapport des Activités de Recherches, Institut D'Oenologiè, Université de Bordeaux II, $1977 \sim 1978$, p. 81.

22) M. Watanabe, Y. Shimazu and M. Uehara, Am. J. Enol. Vitic., 32, 76 (1981). 